\title{
Leprosy-the challenge*
}

\author{
RUTH E. M. BOWDEN \\ Department of Pathology, Royal College of Surgeons, Lincoln's Inn \\ Fields, London WC2, England
}

It is a privilege to pay tribute to the Reverend Philip Thomas Byard Clayton, $\mathrm{CH}, \mathrm{MC}$, DD. Tubby Clayton was a supremely happy man, untidy, absent minded about meetings and agenda, but never about people. He believed that everyone was capable of contributing something towards the welfare of the world. An unmilitary figure, he is one of the most famous Army padres. During the First World War he created peace and beauty close behind the trenches in Belgium. He had a genius for making and encouraging lasting friendships irrespective of rank, race or creed. The lamp he lit at the original Toc $\mathrm{H}$ has never been extinguished. In 1932 he sailed to West Africa. Understandably, he was profoundly shocked by the degradation and squalour endured by people with leprosy who were driven outside the walls of Kano. He was as deeply impressed by the different conditions in the well run leprosarium in Zaria. As a result, he played a significant role in the foundation of BELRA which evolved into LEPRA, a many faceted registered charity.

Relief of suffering and cure of the disease are priorities for LEPRA and all other likeminded organizations but the ultimate aim is to eradicate the disease. It took 200 years for vaccination to abolish smallpox. Fears of diphtheria and poliomyelitis, nightmares of my distant schooldays, have been banished in the United Kingdom by immunization, but they exist elsewhere. The search for a specific leprosy vaccine has been only partially successful. Clinical trials demonstrated that the more easily obtained BCG gives a similar degree of protection. Therefore, it is suggested that newborn children of leprous parents should be given a protective dose of BCG.'

A senior and respected American physician told me that there was no urgency to raise funds for leprosy, 'the disease is declining and in any case all the patients are cared for by the State.' In some ways he is correct. In 1990 WHO published figures for the global prevalence of reported cases of leprosy, coverage by multidrug therapy and the numbers completing this treatment. There were 3.7 million registered cases and an estimated twice that number of unregistered ones. This suggests an incidence of about 11-15 million..$^{2,3}$ This number seems trivial when compared with the huge combined total of 560 million suffering from malaria, schistosomiasis or lymphatic filaria. Although not a killer, leprosy has a disproportionately severe effect upon the social, economic and psychological status

\footnotetext{
* This paper was presented as the Clayton Memorial Lecture, London, on 30 September 1992. The text has been modified where it dealt with information given in a recent publication. ${ }^{5}$
} 
of the patients. The geographical distribution is widespread and unfortunately the use of multidrug therapy is low in the worst affected areas. ${ }^{3}$

Multidrug therapy reduces infectivity in a matter of days, early lesions usually resolve within months or a year or two of beginning treatment. The duration of therapy is finite, the majority of paucibacillary and multibacillary cases are discharged within 9 months and 3 years, respectively, after initiating the therapy. The global relapse rates for

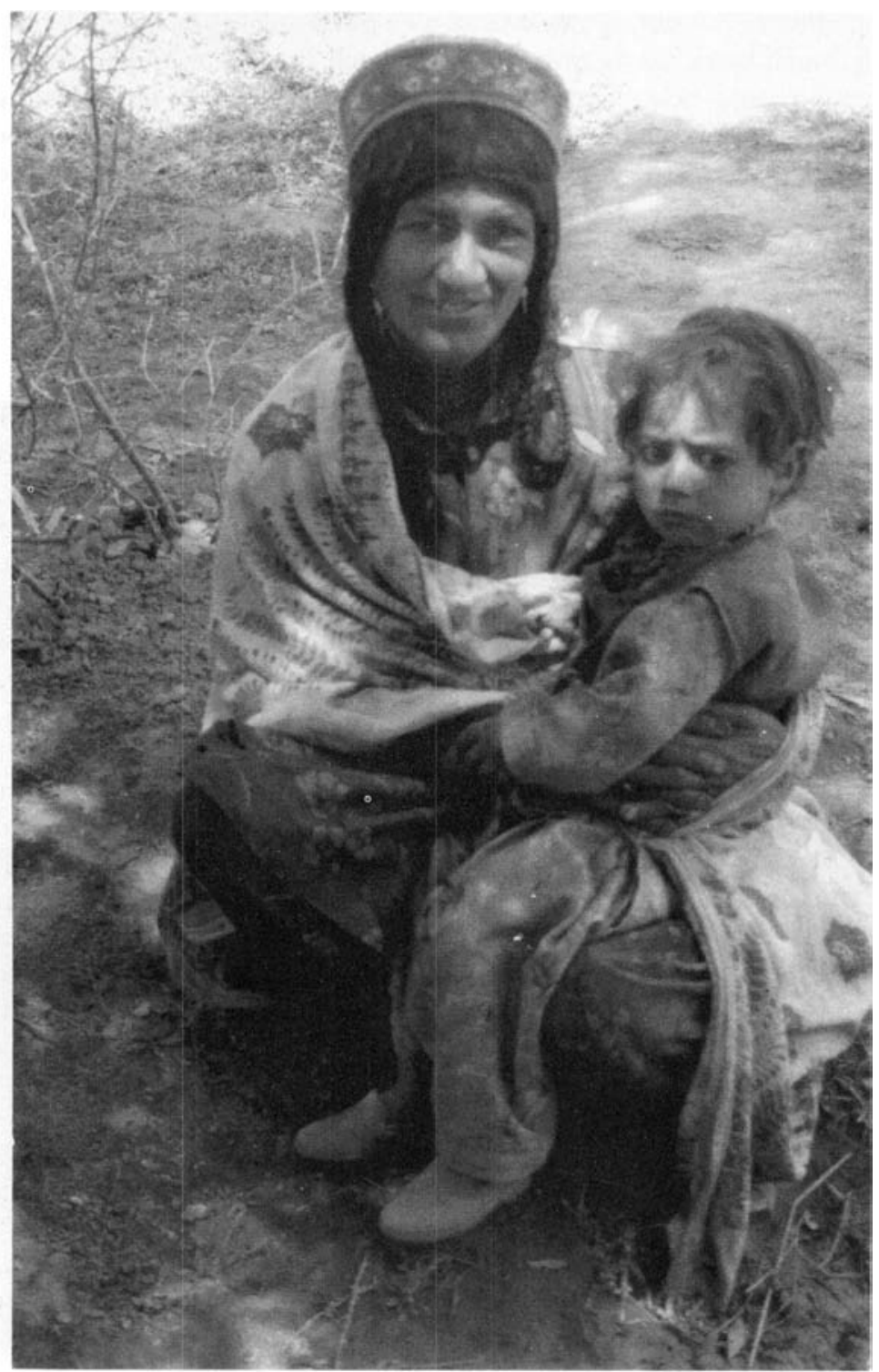

Figure 1. An unveiled Moslem woman and child were checked in the leprosy control programme in the N-W Frontier Province. Her child was astonished to see a white face for the first time. 
paucibacillary and multibacillary cases are $0 \cdot 1 \%$ and $0.06 \%$ per annum, respectively, as against $1-2 \%$ a year for necessarily prolonged dapsone monotherapy which carries the risk of inducing drug resistance. MDT has fewer erythema nodosum leprosum reactions than any other treatment regime. For these reasons the compliance rate of patients ranges from 80 to $90 \%$ in most areas as against a maximum of $50 \%$ for dapsone monotherapy.

I am not competent to discuss the detailed pros and cons of this treatment, but from data presented by WHO, provided it is given sufficiently early, it offers most hope for combating the disease, its disabilities and stigmata. Therefore, WHO now considers it reasonable to aim at eliminating the disease as a public health problem by the year 2000 . Nevertheless, much work needs to be done to reach this more limited target.

Early detection may be difficult for many reasons, including attitudes, local cultures and geography, as exemplified by the vacation experiences of 2 English medical students working with the Marie Adelaide Leprosy Control Team in the North West Frontier Province of Pakistan (Figure 1). Although Moslem, the women are unveiled but no female over 10 years may be examined by a male. This is borne out by the figures for 1989 when only 59 of the 215 new cases were female. ${ }^{4}$ Whilst both extrapriot women were treated with the greatest kindess and courtesy, it is not seemly for local women to do such work.

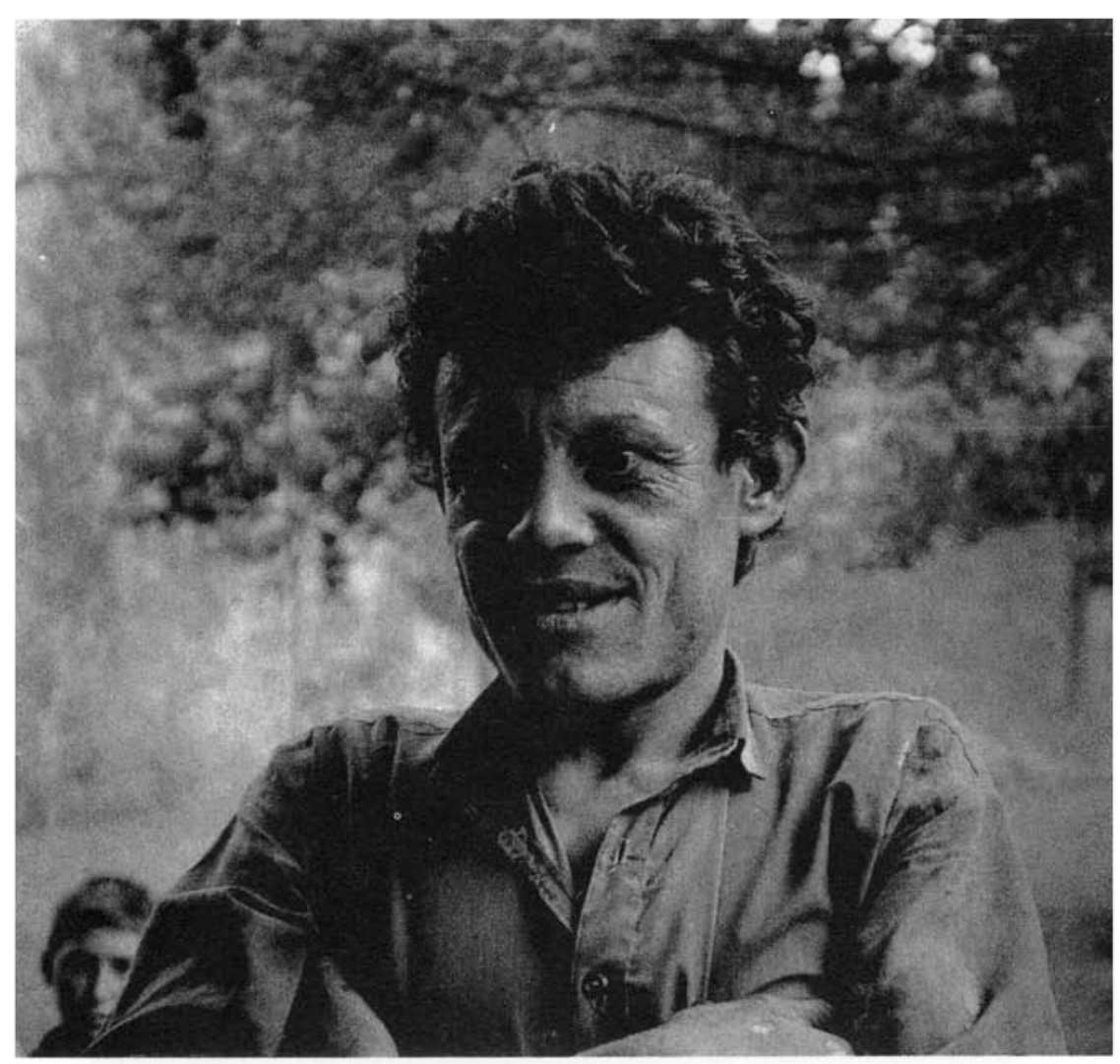

Figure 2. This farm labourer had been forced to leave his home and family when the disease of leprosy was diagnosed. 
The scenery is as magnificent as travel is difficult. The main road from the south to Chitral is $10,000 \mathrm{ft}$ above sea level and impassable for 9 months a year. The most reliable form of transport in some other regions is by donkey or by foot.

Miss Lawman examined hundreds of girls and women and found 3 early cases who had over 60 contacts between them. On a farm the source of infection was a labourer, who had lost his eyebrows and the bridge of his nose. Both hands and feet were ulcerated (Figure 2). He had 48 contacts, of whom 15 were women and 20 children. The farmer's wife had a single scaly patch on the left upper arm, swelling of the radial and ulnar nerves and no feeling in either hand. Extracts from the annual report of this control team for

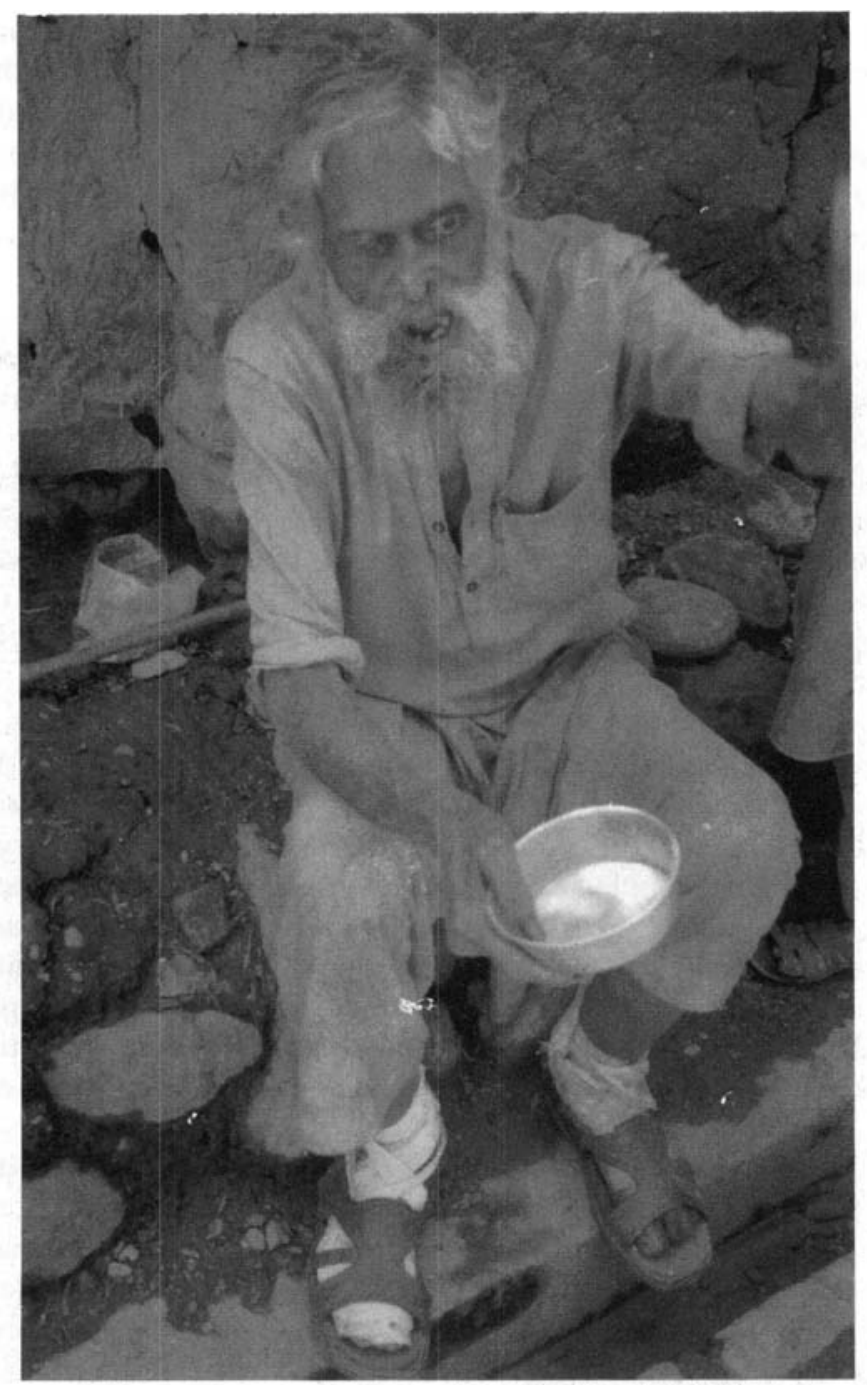

Figure 3. This destitute beggar was homeless, without family, blind and kept alive by the generosity of others. Arrangements were made with his consent for him to have a bed in a mission hospital. 
1989 indicate the scale of arduous and patient work required to find and treat early cases and monitor the contacts.

The WHO data from India for 1980-90 are encouraging. The number of new cases is falling and the discharge rate is increasing. However, the state of some who are discharged from treatment for leprosy is distressing, e.g. a frontiersman was cured, but had lost the tips of all his digits through painless ulceration and destruction of bone from secondary infection and probably ischaemia of bone due to changes in nutrient arteries and deposits of granulomas. Every Sunday in Khartoum two rows of 'burnt out' cases lined the route from the cathedral door, none had any fingers, thumbs or toes. Alms were dropped on to their palms. After making his donations a 5-year-old boy marched back up the line and shook every man by the hand. The delighted smiles and roars of laughter indicated the depth of isolation to which these men were usually subjected. Figure 3 shows an elderly Pakistani who is homeless, destitute, without family and kept alive by the kindness of fellow villagers. He is completely blind with damaged hands and feet, and his leprosy is cured. With his consent, the Marie Adelaide Leprosy Control Group is making arrangements for him to have a bed in the mission hospital in Peshawar as he has neither a bed nor any possessions. If disfigurement and complications are to be avoided, early detection, prompt treatment and supervision are imperative. Delay may lead to disfigurement. Infiltration of the coatings of the eye may be complicated by glaucoma and blindness. When the facial nerve is involved, failure to provide eye drops, protective glasses or perhaps to narrow the palpabral fissure by tarsorrhaphy can result in avoidable blindness due to trauma and infection.

Other disabilities follow paralysis of peripheral nerves. Early signs may be subjective reports of tingling, numbness, 'a feeling of ants crawling on the skin' and even pain, both locally and in the cutaneous distribution of the nerve. Weakness or paralysis in the upper limb lead to characteristic paralytic deformities and to disturbances of skilled and unskilled prehensile movements. The loss of sensation can lead to severe damage from painless cuts and burns. Clawing of the hand means that only the tips of atrophied fingers take all the pressure of gripping a glass, and even holding tools with large handles is insecure. Skilful tasks such as sewing or writing are difficult without a pinch grip and sensitive fingers and thumb. Preserving mobility is vitally important to maintain independence and to prevent psychological amputation and stiffness, which make it impossible to restore movement by tendon transplants. Injury and paralytic deformity are $100 \%$ avoidable by explaining the risks to patients, enlisting their cooperation in regularly carrying out frequent daily passive movements, and wearing lively splints that allow movement and restore normal posture and function. Immobilizing splints are only indicated for short periods after surgery for relief of severe pain or ulceration. Protective gloves may be provided for certain types of work and simple modifications can assist weak hands. ${ }^{5}$

Damage to the common peroneal and posterior tibial nerves results in disturbances of gait and weight bearing with risks of forming callosities and trophic ulcers, risks which are increased in bare foot people. In normal walking the heel strikes in inversion because of the shape of the talus. The heel slides and weight is transmitted through the lateral border of the foot. The toes grip the ground prior to toeing off, which finally involves eversion of the foot and a grinding movement under the head of the first metatarsal, as demonstrated by Paul Brand.

In leprosy the common peroneal is involved at the head of the fibula. This results in 
foot drop, and a high-stepping slapping gait. The foot strikes the ground in marked inversion and under the head of the fifth metatarsal. Gait can be corrected by a lively splint. This has a lateral leg iron with a spring at the level of the ankle joint and a square spur slotted into the heel of the shoe, ${ }^{5}$ and whether wearing long trousers, shorts, a dhoti or a skirt, it is not only less conspicuous than the conventional toe-raising spring which has the spring attached at the level of the toe crease of the shoe, but also it is more efficient and less likely to be associated with a contracture of the calf muscle.

Lesions of the posterior tibial nerve commonly occur at the ankle, producing complete anaesthesia of the sole of heel and foot. Paralysis of the intrinsic muscles produces clawing of the toes. If shoes are worn callosities form on the dorsum of the proximal interphalangeal joints. Wasting of soft tissue, including muscles, reduces the surface area for weight bearing. The risk of ulceration is grave. The clawed toes can be corrected by an insole. This must go the whole length of the foot. Plasterzote has been advocated as insoles can be tailor made for each individual. Well fitting leather shoes are ideal but these are costly and conspicuous in bare foot communities, making patients unwilling to wear them despite the necessity for doing so.

Detecting early signs of disturbances of cutaneous functions requires a carefully taken history, avoidance of leading questions, visual inspection for signs of sweating, patterns of papillary ridges, atrophy of the pulps of fingers and toes, and signs of callosities, fissures or ulceration. Tests need to be conducted in a quiet room. They are time consuming and each one should be demonstrated and explained to a patient who is at ease and neither hungry nor needing to go to the lavatory. As both patient and examiner have to concentrate, frequent pauses are desirable. Calibrated equipment and accurate recording of progress are necessary. This does not entail sophisticated electronic equipment which has no place in routine clinical and field work. However, reliable, repeatable objective results are feasible. Measurement of nerve conduction rates and electrical reactions are only essential in research and in specialized base hospitals.

Equipment, which can be made by any hospital technician or handyman, has been described in detail in a previous publication, together with a few items that are obtainable commercially. ${ }^{5}$

Simple mapping of areas of loss or disturbance of sensibility can be recorded photographically or on standard diagrams. More elaborate recording has been advocated, but one suspects that this will be more time consuming but no more accurate than simple mapping. Practical experience will tell.

Disturbances of gait are revealed by examining soles and uppers of footwear. With an uncorrected foot drop heels are lightly worn, the outer border of fore foot and toe of the sole are heavily scuffed. Intrinsic palsy makes a deep toe crease on the upper part of the shoe whilst the toe of the sole is unworn.

Footprints in wet sand, or more conveniently made on paper by standing on a large ink pad, are instructive. More costly equipment such as Harris' mats, ${ }^{6}$ can give calibrated estimates of pressure. The presence and location of callosities are danger signals and indicate urgent readjustment of lively splints or insoles.

The role of reconstructive surgery cannot be discussed fully, but 2 points are worth noting. The isolated lesions of the ulnar nerve at the elbow, the median at the wrist, the common peroneal at the knee and posterior tibial at the ankle joint are subcutaneous and at relatively low temperatures. However, each of these locations is proximal to a restrictive fibro-osseus tunnel. Carpal and tarsal tunnel syndromes are well recognized 
and early, rather than late, release of pressure is necessary if serious structural nerve damage is to be avoided. Could the severity of these leprous lesions be lessened by early operation combined with steroids which are known to relieve pain ${ }^{7}$ The second point relates to the recent publication of results of resection and repair of localized lesions by autogenous muscle grafts in carefully selected cases. ${ }^{8}$ Tendon transplants can alleviate mechanical defects, but regeneration of nerves is the only method of restoring sensation. Results of the pilot study of this operation are encouraging. There is no problem of rejection of the graft, no donor nerves are sacrificed. The criteria for selection of patients and the results are shown in Tables $1-5$. These patients and those in the extended trials in Ethiopia and Brazil have to be followed up carefully for several years to avoid raising false hopes.

If the limited objective set by the WHO, the final goal of eradication of leprosy, is to be achieved, the public and the medical and paramedical professions need to be aware of problems, alert to possibilities of cure and rehabilitation, and active in instituting early

Table 1. Criteria of selection for repair by muscle graft*

Informed consent

At least 18 months stable complete motor and sensory paralysis

Completion of 6 months drug treatment

No active ulceration

Not receiving steroids

*All tables are based on the data of Pereira, Curtis \& Turk. ${ }^{7}$

Table 2. Pilot study of muscle graft repair of nerves

\begin{tabular}{ll}
\hline Number of patients & $10(7 \mathrm{M}, 3 \mathrm{~F})$ \\
Age range (years) & $17-37$ \\
& \\
Type of disease & 7 \\
Borderline tuberculoid & 1 \\
Borderline lepromatous & 2 \\
Lepromatous & \\
\hline
\end{tabular}

Table 3. Nerves repaired by muscle graft in the pilot study

\begin{tabular}{ll}
\hline Number of nerves grafted & 12 \\
$\quad$ Median nerves & 3 \\
$\quad$ Posterior tibial nerves & 9 \\
Duration of disease (years) & $4 \cdot 5-12$ \\
Duration of paralysis (years) & $1 \cdot 5-7$ \\
Length of grafts (cms) & $2 \cdot 5-6$ \\
\hline
\end{tabular}


Table 4. Information of progress given by patients

No recovery of movements

(Irreversible structural changes occur in muscles after prolonged denervation)

$7 / 12$ reported improved sensory function

$5 / 9$ reported ability to distinguish between walking on stones and treading on thorns*

$0 / 12$ had no signs of recovery

$2 / 9$ had reduction of ulcers and fissures on feet

* At the time of publication of this paper 14/20 reported this finding.

Table 5. (Pre) and postoperative clinical findings for 12 nerves (Duration of follow-up 8-18 months)

\begin{tabular}{llr} 
Tinel's sign distal to lesion $(\mathrm{cms})$ & $(0 / 12) 0$ in \\
& $4 * 1-16$ & \\
Sweating & $(3 / 12)$ & 9 \\
Joint position sense & $(0 / 12)$ & 11 \\
Response to 10 gm PIN & $(0 / 12)$ & 5 \\
Response to 20 gm HAIR & $(0 / 12)$ & 4 \\
\hline
\end{tabular}

* Progressed to but not beyond distal suture line. Vibration sense was present in 9 preoperative cases lost immediately after operation, recovered in $11 / 12$.

and appropriate treatment. Therapy includes the psychological, social and economic rehabilitation of patients which begins pari passu with medication. A change in the attitude of the public to the sufferers and to the disease forms an essential part of the process of social reintegration of patients. Figures 4 and 5 summarize the plan of action and characteristics of therapy.

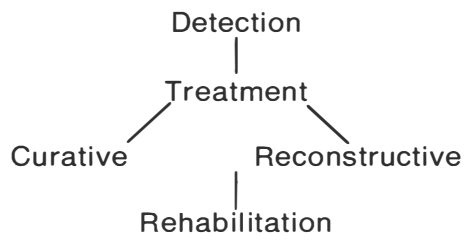

Figure 4. The plan of action in treating leprosy.

\section{Appropriate \\ Educational \\ Intensive \\ Overseen \\ Understanding}

Figure 5. The characteristics of sound therapy. 


\section{Acknowledgment}

Figures 1-3 are published by kind permission of Miss Sarah Lawman, many of whose photographs were shown as slides in the lecture.

\section{References}

1 World Health Organization. Immunological problems in leprosy research: 2 (1973). Reproduced in Lepr Rev, 1974; 45: 275.

2 World Health Organization. Multidrug therapy for leprosy: an end in sight. Geneva (1988). 1-32.

${ }^{3}$ World Health Organization. Towards elimination of leprosy: Leprosy Control Programme (1992). 1-12.

${ }^{4}$ Marie Adelaide Leprosy Centre. Annual Report 1989, and Silver Jubilee of leprosy control measures in N.W.F.P. and celebrations marking the establishment of leprosy control in District Swat (1990).

5 Palande D, Bowden REM. The early diagnosis of damage to nerves in leprosy. Lepr Rev, 1992; 63: 60-72.

${ }^{6}$ Duckworth T. Pedobarography, in The Foot ed. Helal. B and Wilson. D. Churchill Livingston, Edinburgh, 1988, 108-130.

7 Personal communication.

${ }^{8}$ Pereira JH, Palande DD, Subramanian A, Narayanakumar TS, Curtis J \& Turk JL. Denatured autologous muscle graft in leprosy. Lancet 1991; 338: 1239-40. 